\section{La violencia en la \\ concepción \\ hobbesiana \\ del estado moderno}

\author{
Jorge Zeledón*
}

\section{RESUMEN}

Se analiza el discurso filosófico -politico de Thomas Hobbes y su significación en la configuración del pensamiento y la institucionalidad del Estado moderno enfatizándose en el carácter monopólico que adquiere el poder político.

\section{PALABRAS CLAVES}

Violencia, Estado, Estado de Guerra, Estado Moderno, Guerra de todos contra todos.

\footnotetext{
* Licenciado en Filosofía. Encargado de Cátedra de Filosofía. UNED. Profesor de Filosofía en los Estudios Generales, Sede Rodrigo Facio y en la Sede Occidente, UCR

Rec. 14-6-05 / Acep. 28-9-05
}

\begin{abstract}
This article analyzes Thomas Hobbes political-philosophical discourse and its relevance in the formulation of the ideology and the institutionalization of the Modern State by, emphasizing on the monopolistic nature of the political power.
\end{abstract}

\section{KEYWORDS}

Violence, State, War Condition, Modern State, War of everyone against everyone

\section{INTRODUCCIÓN}

En el presente artículo se realiza una caracterización de la violencia en términos de su permanente presencia en las sociedades humanas, hecho que Hegel destacó cuando afirmó que la humanidad como tal presenta su génesis en la lucha entre el amo y el esclavo por la sobrevivencia.

El monopolio de poder reside en un Estado que condensa la violencia de cada uno de los individuos miembros de la sociedad. Mediante un Contrato cada individuo cede esta capacidad de ejercer violencia a una entidad abstracta llamado Estado que empleará el temor sistemático para disuadir a los hombres de provocar una guerra de todos contra todos, que tornaría inviable a las sociedades humanas. 
Desde una visión antropológica pesimista Hobbes hace descansar la paz y la posibilidad de la vida social en el temor a la muerte y en el hecho de entregar a un poder soberano, el derecho de matar legítimamente.

Analizamos algunos criterios de Macpherson que percibe y relaciona de manera conflictiva la teoría política de Hobbes, con una sociedad posesiva de mercado, desde la cual se podría explicar las ansias de poder de los seres humanos.

\section{Estado de guerra como expresión de una igualdad abstracta}

La violencia y su carácter latente, presta a manifestarse en todas sus consecuencias- propia de la condición de los hombres en "estado de guerra" - constituye uno de los elementos que más visiblemente han perdurado, a través del tiempo, dentro de la más difundida visión hobbesiana acerca de la organización social y política de la especie humana. Esta violencia, originada -según Hobbes- en la ausencia de un poder común que infunda temor a todos los seres humanos, se resume en la expresión latina
"Bellum Omnium Contra Omnes" y se basa en la hipótesis lógica, con carácter de recurso heurístico elaborada por el propio Hobbes, de la presunta existencia de un estado de guerra o de naturaleza, que dicho autor fundamenta en la tendencia natural de los hombres que los lleva a:

... destrozarse mutuamente, la cual deriva de sus pasiones, pero más que todo de su vanidad, agreguemos ahora el derecho de todos, que permite atacar $\mathrm{y}$ defenderse con el mismo derecho y que es el origen de los celos y de las eternas sospechas de todos contra todos. Si consideramos a cuan difícil es guardarse de los enemigos, aún poco numerosos y mal armados cuando atacan con la intención de adelantársenos y oprimirnos, es imposible negar que el estado natural de los hombres, antes de que se hubiesen constituido en sociedad, fue guerra, y no la guerra simplemente, sino la guerra de todos contra todos." (Bellum Omnium Contra Omnes). (Hobbes, 1966:70). 
En estas expresiones de Thomas Hobbes (1588-1679), presentes en su obra De Cive (1647) y en otras, expuestas en el Leviatán (1651), nos encontramos con las referencias más genéricas y universales acerca del papel que juega la violencia dentro de su pensamiento político, y que sintetiza en su conocida frase:

El hombre es un Dios para el hombre, pero también el hombre es un lobo para el hombre. (Homo hominis lupus) (Hobbes, 1966:43).

De tal manera que:

...la perversidad de los malos pone incluso a los buenos en la obligación de recurrir si quieren protegerse, a las virtudes bélicas, la violencia y la astucia, o mejor dicho, a la rapacidad bestial." (Hobbes, 1966:43).

De acuerdo con Norberto Bobbio, en Hobbes nos encontramos con la "primera teoría del Estado Moderno", profundamente influida por el método empírico-analítico de Galileo y sus descubrimientos en el campo de la Mecánica, a partir de lo cual Hobbes ve al hombre como un sistema mecánico de materia en movimiento, una máquina que: ...trata de perpetuar su movimiento. Lo hace moviéndose hacia cosas de las que calcula que conducirían a su movimiento continuado y alejándose de las que no conducen a él. El movimiento de acercamiento se llama apetito o deseo, y el de alejamiento se llama aversión. Alguno de los apetitos y aversiones, como los del alimento, se hayan impresos en máquinas, pero muchos proceden de la experiencia y comprobación de sus efectos sobre nosotros mismos o sobre otros hombres. (Macpherson,1979:39).

Entre estos últimos tipos de aversión se encuentra el miedo, una de las bases de esta teoría según la cual, en el hipotético "estado de naturaleza" y en el marco de la guerra de todos contra todos, propia de dicho estado, prevalecerá el miedo desorganizado, expresado en el temor común a la muerte violenta; situación que llevaría a la necesidad de superar ese estado de cosas, teniendo en cuenta para ello que:

Las pasiones que inclinan a los hombres a la paz son el temor a la muerte, el deseo de las cosas que son necesarias para una vida conforta- 
ble y la esperanza de obtenerlas por medio del trabajo (Hobbes, 1984:105).

Podemos encontrar en el planteamiento hobbesiano, lo que Macpherson denomina como obligación política en una sociedad de mercado, a partir de la consideración de la igualdad de los hombres por naturaleza (Leviatán, capítulo XIII y de Cive capítulo primero) que los conduce a aspirar a las mismas cosas y los torna necesariamente en enemigos, lo que constituye el germen de toda violencia a partir de la cual se vuelve indispensable, en aras de superar sus devastadoras consecuencias, el establecimiento de un poder común: Un Soberano o poder absoluto, perpetuo y garante de la seguridad y bienestar de todos sus súbditos.

Puede apreciarse cómo todas esas pasiones o apetitos son propios del hombre civilizado, lo cual nos estaría indicando que:

... el estado de naturaleza de Hobbes o la condición natural de la humanidad nos refiere al hombre "natural" contrapuesto al hombre cuyos deseos son específicamente civilizados, que el estado de naturaleza es la condición hipotética en la que los hom- bres tal y como son ahora se hallarían necesariamente si no existiera un poder común capaz de intimidarlos a todos" (Macpherson, 1979:28).

Al respecto nos dice Hobbes, en relación con el ya referido estado de naturaleza:

Acaso puede pensarse que nunca existió un tiempo o condición en donde se diera una guerra semejante, y en efecto; yo creo que realmente nunca ocurrió así, en el mundo entero; pero existen varios lugares donde viven ahora de ese modo. Los pueblos salvajes en varias comarcas de América, si se exceptúa el régimen de pequeña familia cuya concordia depende de la concupiscencia natural, carecen de gobierno en lo absoluto, y viven actualmente en ese estado bestial al que me he referido (Hobbes, 1984:104).

Dando evidencia del impacto que ejercieron los conflictos políticos y religiosos, como la guerra civil inglesa entre el rey Carlos I y el parlamento Largo (1642-1648), y la guerra de los treinta años- en Alemania- entre católicos y protestantes, añade Hobbes: 
De cualquier modo, puede percibirse cuál será el género de vida cuando no exista un poder común que temer, pues el régimen de vida de los hombres que antes vivían bajo un gobierno pacífico, suele degenerar en una guerra civil (Hobbes, 1984:104).

Sí, evidentemente, el estado de guerra que caracterizaría la condición natural del ser humano (sistema mecánico de materia en movimiento) es, ante todo, como hemos venido exponiendo líneas atrás, una construcción lógica con propósitos heurísticos, que permite también mostrar los devastadores efectos de la guerra civil, pues:

En una situación semejante no existe oportunidad para la industria, ya que su fruto es incierto; por consiguiente no hay cultivo de la tierra, ni navegación, ni uso de los artículos que pueden ser importados por mar, ni construcciones confortables, ni instrumentos para mover y remover las cosas que requieren mucha fuerza, ni conocimiento de la faz de la tierra, ni cómputo del tiempo, ni artes, ni letras ni sociedad, y lo que es peor, existe continuo temor y peligro de muerte violenta, y la vida del hombre es solitaria, pobre, tosca, embrutecida y breve (Hobbes, 1984:103).

Esta primera teoría moderna del estado moderno, históricamente, parte de lo que:

es una lucha larga y sangrienta por la unidad del poder: Esta unidad es resultado de un proceso simultáneo de liberación frente a una autoridad tendencialmente universal (el papado o los obispos de las iglesias reformadas), que por su orden espiritual se proclama superior a todo el poder civil, de unificación frente a las instituciones menores, asociaciones y corporaciones, ciudades que constituían en la sociedad medieval un permanente peligro de anarquía. Como consecuencia de esos dos procesos, la formación del Estado moderno viene a coincidir con el reconocimiento y consolidación de la supremacía absoluta del poder humano. Esta supremacía acaba justamente de recibir un nombre en el siglo XVI: se llama soberanía (Bobbio en Hobbes, 1966:9). 
Las guerras religiosas o las pretensiones corporativas de algunos sectores serían entonces -según Hobbes- los mayores venenos para ese estado civil representado en el soberano, de cuyos actos se convierte en autora una gran multitud.

\section{La sociedad posesiva de mercado}

La situación de guerra de todos contra todos, vista como una manifestación del carácter negativo de la naturaleza humana, tradicionalmente ha servido para justificar el carácter "necesario" del Estado soberano. En este sentido, Macpherson considera que ese planteamiento "tradicional" constituye una simplificación, puesto que Hobbes parte de las condiciones psicológicas del hombre formado en una sociedad de mercado y solo tangencialmente se refiere al hipotético hombre en estado de naturaleza.

La aceptación del referido "punto de vista tradicional" supone asumir que la percepción de Hobbes sobre la naturaleza humana, es una abstracción. Por el contrario, si se asume que las referidas condiciones de la conducta de los hombres obedecen a un tipo de sociedad como es el caso de la Inglaterra del siglo XVII, vista -en términos de Macpherson- como una sociedad posesiva del mercado, la visión Hobbesiana del hombre considerado como una máquina caracterizada por un incesante afán de poder, a partir de sus apetitos $y$ aversiones, constituye un reflejo de ese tipo de sociedad. Por lo que dicha realidad le permite inferir la inclinación de la humanidad entera hacia " un perpetuo e incesante afán de poder, que cesa solamente con la muerte" (Hobbes, 1984:79).

Lo anterior, nos permite afirmar que la naturaleza humana hobbesiana no es abstracta, puesto que, mas bien, constituye una descripción de una conducta de una sociedad determinada por relaciones mercantiles con pretensiones univerzalizantes.

¿De dónde emana ese poder, pues, que tanto afana a los seres humanos y que, el autor del Leviatán define como medio para la obtención de algún beneficio. Hobbes divide analíticamente ese poder en: a) poder natural, que consiste en las eminencias de las facultades del cuerpo o de la inteligencia y b) poder instrumental, que se adquiere a partir de las facultades mencionadas en el punto anterior 
(como una extensión y sirve como medio para adquirir más poderes, como: riqueza, reputación, amigos. $\mathrm{Al}$ respecto, señala Macpherson:

El Poder natural de un hombre no se define como su capacidad natural (fuerza, prudencia, etc), sino como eminencia de sus facultades... sobre las de los demás es lo que permite adquirir poderes instrumentales (riquezas, reputación, amigos, etc))...El poder de un hombre no es una entidad abstracta, sino relativa" (Macpherson,1979:42-42).

Podemos afirmar, en consecuencia, que ese excedente de poderes entre los seres humanos, considerado a partir de la eminencia de las ya mencionadas facultades, se constituye en uno de los elementos que explican la desigualdad social concreta, y la necesidad de su sanción positiva dentro del estado civil; esta sanción habrá de operar de tal manera que queden protegidos los intereses a partir de los cuales se configura el orden social ("la sociedad posesiva" de mercado en términos de Macpherson).

En la concepción negativa del hombre expuesta por Hobbes como ya hemos visto, el descubrimiento de la condición natural del ser humano deriva del estudio del ser social de su época. El discurso político hobbesiano condensa la socialización de una forma de vida emergente, para ello metodológicamente procede de la siguiente manera: a) parte de la observación del hombre inglés, que abstrae, de ese concepto del hombre una naturaleza humana; b) expresa la esencia de esa naturaleza como un estado de guerra; c) determina el estado de guerra como la justificación para el surgimiento de un poder absoluto. Este poder puede ser entendido como la ley absoluta, como sacrificio.

El nuevo orden (el mercado), descansa en un poder que para Hobbes -necesariamente- debe ser absoluto, pues el mismo, al provenir de un pacto entre los hombres libres, fundamenta toda moral, por tanto, el empleo de cualquier recurso que garantice la permanencia del orden social. Este orden promueve, en forma abstracta, la igualdad; pero en realidad, exige como premisa la desigualdad, que origina la lucha permanente en el seno de la sociedad. Esta conflictividad que solo puede ser resuelta por un Estado coercitivo que, tendencialmente, monopolice el empleo de todo un aparato especializado en ejercer el poder mediante la violencia. 
El éxito en el empleo de la violencia constituye una de las instancias principales del poder político; su empleo sistemático se fundamenta en el hecho de que la conservación de la vida y la seguridad, son valores centrales de las sociedades humanas.

Así, podríamos caracterizar la violencia política en el pensamiento político de Tomas Hobbes, como aquella instancia legítima a la cual apela el poder político, para garantizar las condiciones mínimas de la reproducción de un sistema que depende del respeto de los contratos entre los hombres:

Donde no hay un poder común, la ley no existe; donde no hay ley no hay justicia (Hobbes, 1984:1).

Desde luego, Hobbes se refiere a las leyes positivas que regularán las relaciones de los hombres, una vez fundada la sociedad política; si bien es verdad, en estado de naturaleza también existen leyes como justicia, equidad, modestia, piedad, etc; que no podrían ser cumplidas porque contradicen la naturaleza humana, cuya inclinación conduce a los hombres por el camino del mal y la violencia. Sólo el poder representado por el Leviatán, posibilita la realización de tales leyes.
Las leyes de naturaleza (tales como las de justicia, equidad, modestia, piedad, en suma, la de haz a otros lo que quieras que otros hagan por ti) son, por si mismas, cuando no exista el temor a un determinado poder que motive su observancia, contrarias a nuestras pasiones naturales, las cuales nos conducen a la parcialidad, al orgullo, a la venganza y cosas semejantes (Hobbes, 1984:137).

\section{La eficacia política de la violencia}

El temor que es capaz de inspirar el Estado radica básicamente en su capacidad para castigar.

Los pactos que no descansan en la espada no son más que palabras, sin fuerza para proteger al hombre de modo alguno (Hobbes. 1984:137).

La definición misma de pena permite entender que en la teoría política de Hobbes, la violencia es caracterizada en dos niveles:

- Como instancia legítima del poder político y

- Como intervención física. 
En cuanto instancia legítima, el poder político descansa, si bien es cierto que no de manera exclusiva, sí, tendencialmente, en el empleo de la violencia como monopolio del Estado.

En cuanto a la intervención física, hace referencia al éxito que han demostrado tener las sanciones físicas, como medio para modificar la conducta de los individuos.

Una pena es un daño infligido por la autoridad política sobre alguien que ha hecho $\mathrm{u}$ omitido, lo que se juzga por la misma autoridad como una trasgresión de la ley, con el fin de que la voluntad de los hombres pueda quedar, de este modo, mejor dispuesta para la obediencia" (Hobbes, 1984:254).

Hobbes deriva la necesidad y legitimidad de la violencia como estructura y práctica del poder:

a) De la naturaleza de los seres humanos y; b) De la necesidad del orden, entendido como el imperio de la ley que se opone al caos.

Una reflexión final sobre la justificación de la guerra de todos contra todos: según Hobbes, la violencia destructiva que de forma potencial radica en cada uno de los hombres se origina en la paradójica realidad de la igualdad, que provoca que unos intentemos dominar a otros (la dialéctica de desear el deseo de los otros, según Hegel). De esta supuesta igualdad hobbsiana deriva una competencia que ante la falta de un poder estatal se convierte en guerra, por lo que los hombres no experimentan placer alguno de estar juntos sin que exista un poder incapaz de imponerse a todos ellos, esta tesis de la incapacidad de sociabilidad de los hombres es radicalmente anti- aristotélica, es decir por creer que poseemos una naturaleza social, no podemos desarrollar un mínimo de sociedad. Construir lo social sobre algo inexistente es para el autor del Leviatán condenarnos multiplicar los engaños y quimeras.

\section{BIBLIOGRAFIA}

Hobbes, Thomás: Leviatán. D.F. Fondo de Cultura Económica, 1984.

Hobbes, Thomás: Del ciudadano. Caracas Instituto de Estudios Políticos, 1966.

Macpherson, CB: La teoria politica del individualismo posesivo. De Hobbes a Locke, Editorial Trotta. Madrid, 1979.

Chevalier, Jean Jacques. Los grandes textos politicos. Desde Maquiavelo a nuestros días. Editorial Aguilar, 7ed. Madrid, 1977. 
Cedeño Castro Rogelio. Religión Civil o Religión de Estado, Universidad Nacional, Heredia, Costa Rica, 2004.

Frank J.Hinkelammert. El Sujeto y la ley. EUNA, 2003.

Gallardo Helio. Siglo XXI. Militar en la izquierda. Editorial Arlequín. San José, Costa Rica, 2005. Siglo XXI. Producir un mundo. Editorial Arlequín, 2006.

Michel Onfray. Antimanual de Filosofía. Editorial Onfray, 2005.

Peter Sloterdijk. Crítica de la Razón cínica. Ediciones Siruela, 2003. 